\title{
Abstract
}

\section{BRCA1 Mutation Analysis in a Portuguese Population with Early-Onset Breast and/or Ovarian Cancer}

Raquel Soares, Ronald van Eijk, Aureliano Dias, Mónica Botelho, Carla Costa, Isabel Amendoeira, Carlos Lopes, Peter Devilee and Fernando Schmitt

Institute of Molecular Pathology and Immunology of the University of Porto, Porto, Portugal Department of Pathology, Portuguese Institute of Oncology, Porto, Portugal Department of Human Genetics, Leiden University, The Netherlands

The aims of our study were: (1) to detect disease-associated BRCA1 mutations in a series of Portuguese patients with breast and/or ovarian cancer; (2) to evaluate the expression of molecular markers of biological behaviour, namely ER, proliferative index, c-erb-B2, p53, sialyl-Tn and angiogenic index in a series of hereditary breast cancer (HBC) in relation to sporadic cases. We selected 65 patients consecutively diagnosed in our institute with earlyonset breast cancer. Three patients with ovarian cancer were also studied. The breast cancer cases were divided into hereditary $(\mathrm{n}=33)$ and sporadic $(\mathrm{n}=32)$ according to BCLC criteria. BRCA1 mutations were studied by PTT and Fragment Analysis. Direct sequencing was performed in the positive cases. Two cases with alteration in BRCA1 gene were observed. One ovarian carcinoma presented a mutation in exon 11 (3444delAAAT). A deletion in intron 1 was observed in one breast cancer case (IVS18+ 80delA). These two mutations were not previously described according to BIC web site. The histologic parameters of breast cancer cases were evaluated in tissue sections and the markers were studied by immunohistochemistry. HBC cases presented younger age of onset, higher angiogenic and proliferative indexes. There were no significant differences in tumour size, nodal status, histologic grade, ER status and expression of c-erb-B2, p53 and sialyl-Tn. In conclusion, we detected two new BRCA1 mutations in a series of early-onset breast and/or ovarian cancer patients of Portuguese origin. This is the first description of BRCA1 mutations in a Portuguese population. 


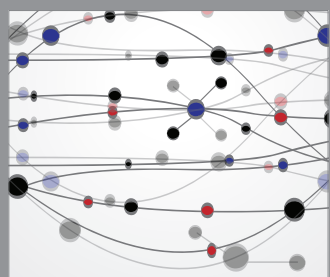

The Scientific World Journal
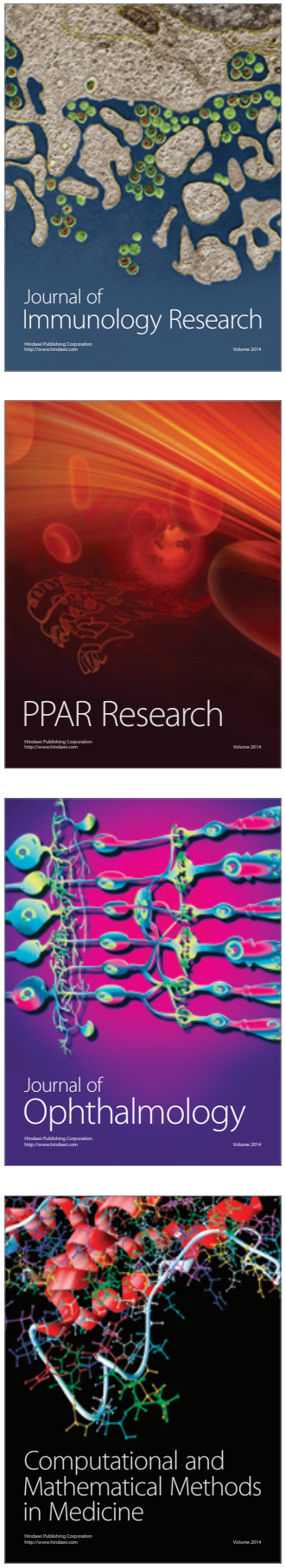

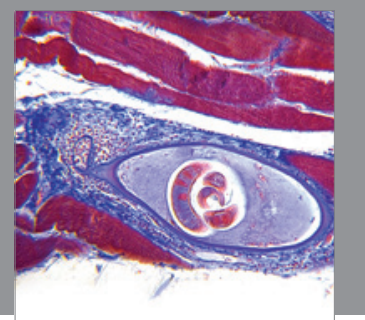

Gastroenterology

Research and Practice
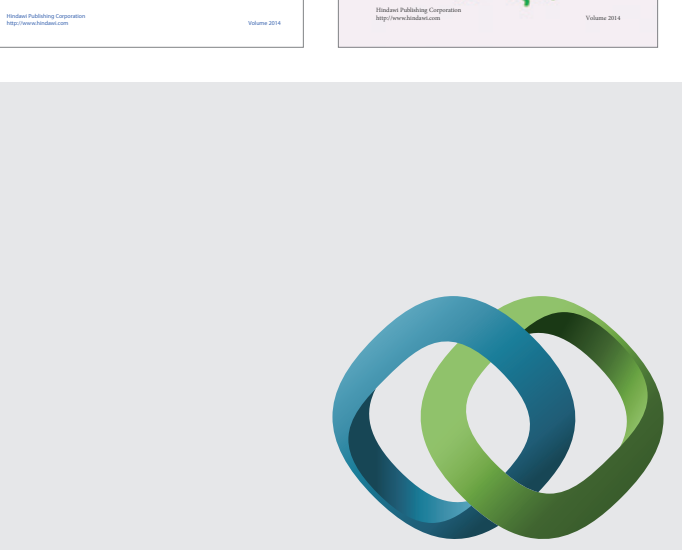

\section{Hindawi}

Submit your manuscripts at

http://www.hindawi.com
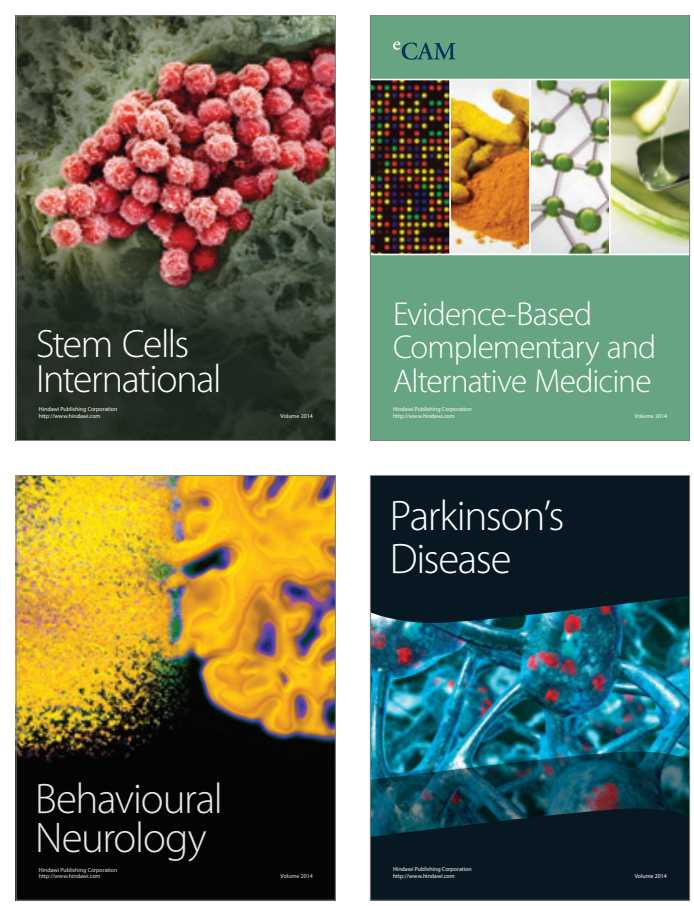

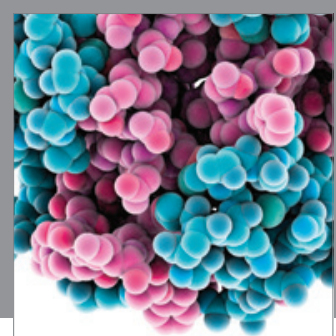

Journal of
Diabetes Research

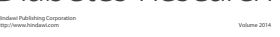

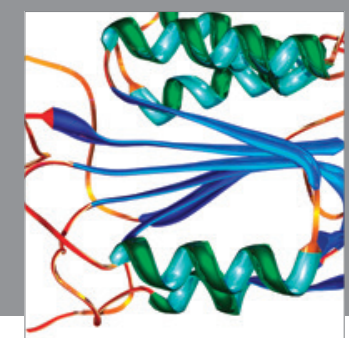

Disease Markers
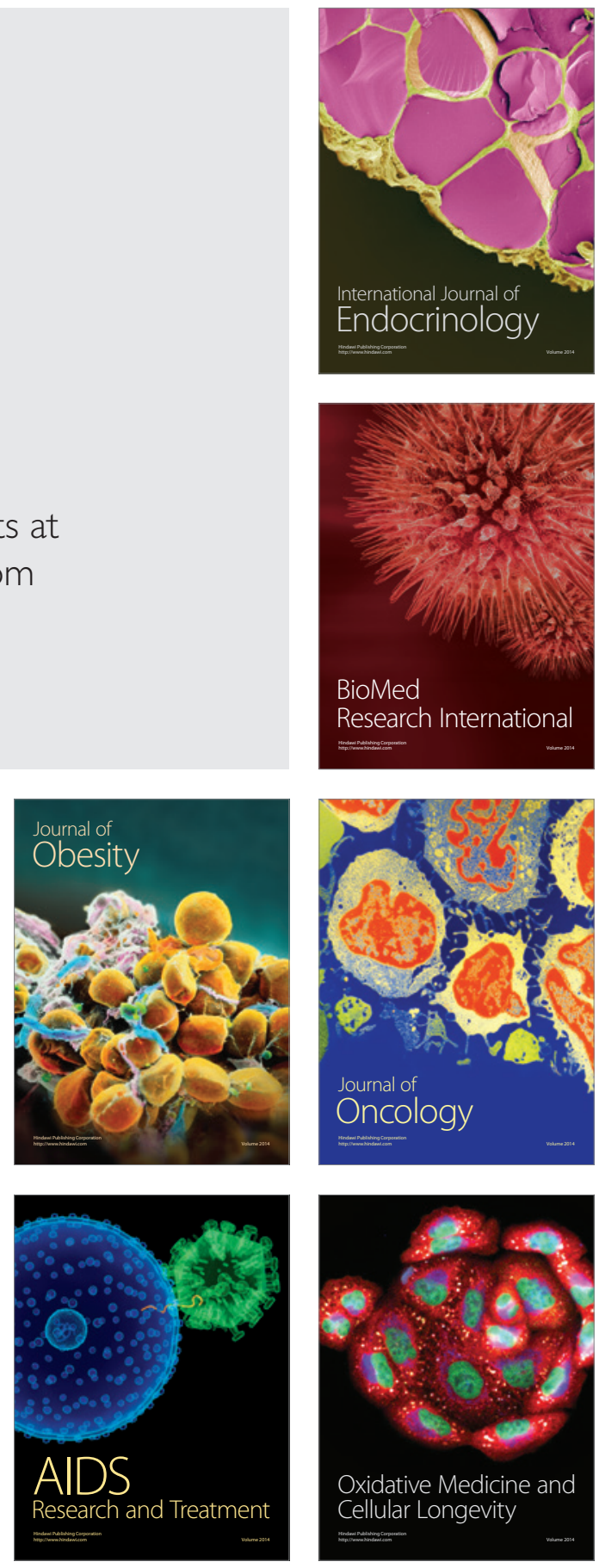